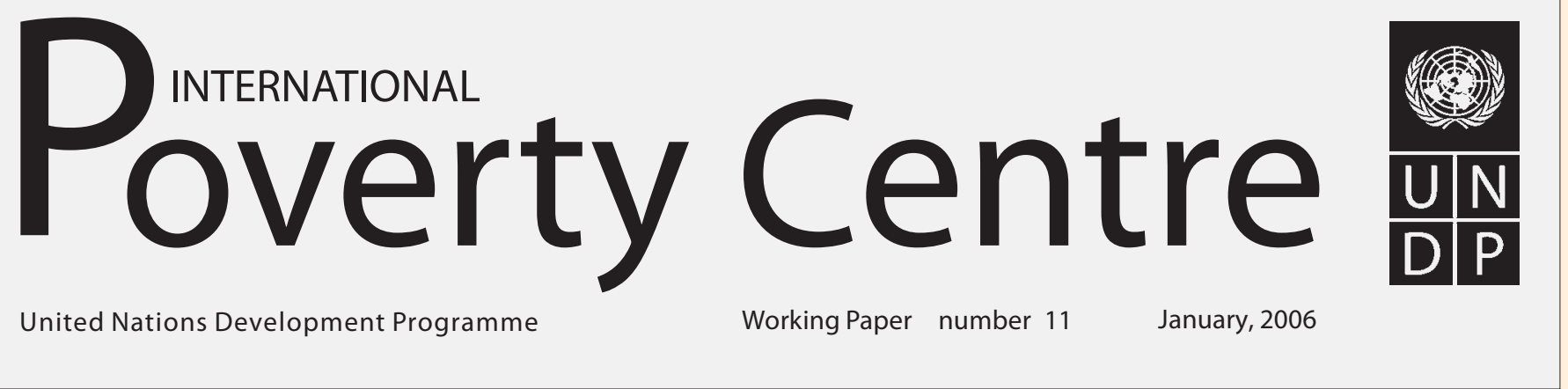

\title{
MEASURING THE IMPACT OF PRICES \\ ON INEQUALITY: WITH APPLICATIONS \\ TO THAILAND AND KOREA
}

Hyun H. Son

International Poverty Centre,

United Nations Development Programme

and

Nanak Kakwani

International Poverty Centre,

United Nations Development Programme 


\title{
Copyright $\odot 2006$
}

United Nations Development Programme International Poverty Centre

\author{
International Poverty Centre \\ SBS - Ed. BNDES, $10^{\circ}$ andar \\ 70076900 Brasilia DF \\ Brazil
}

povertycentre@undp-povertycentre.org

www.undp.org/povertycentre

Telephone +55 6121055000

Fax +556121055001

\section{Rights and Permissions}

All rights reserved.

The text and data in this publication may be reproduced as long as the source is cited.

Reproductions for commercial purposes are forbidden.

The International Poverty Centre's Working Papers disseminates the findings of work in progress to encourage the exchange of ideas about development issues. Our main objective is to disseminate findings quickly, so we compromise and bear with presentations that are not fully polished. The papers are signed by the authors and should be cited and referred accordingly. The findings, interpretations, and conclusions expressed in this paper are entirely those of the authors. They do not necessarily represent the view of the International Poverty Centre or the United Nations Development Programme, its Administrator, Directors, or the countries they represent.

Working Papers are available online at http://www.undp.org/povertycentre and subscriptions might be requested by email to povertycentre@undp-povertycentre.org 


\title{
MEASURING THE IMPACT OF PRICES ON INEQUALITY: WITH APPLICATIONS TO THAILAND AND KOREA*
}

\author{
Hyun H. Son ${ }^{* *}$ and Nanak Kakwani
}

\begin{abstract}
This paper develops a new methodology to compute social cost of living indices. These indices indicate whether or not price changes have a favourable (or unfavourable) impact on the welfare of the poor. The indices are derived on the basis of two alternative classes of social welfare functions. The methodology developed in the paper is applied to compute social cost of living indices for Thailand and Korea. The empirical results show that changes in prices have generally affected the poor more adversely than the non-poor.
\end{abstract}

Keywords: Social Cost of Living; Democratic and Plutocratic costs of living indices; Social expenditure function; Social budget shares; Atkinson's inequality measures; Substitution bias.

\footnotetext{
*We would like to acknowledge detailed comments from three anonymous referees, which helped to improve the paper enormously. We are particularly grateful to Professor Jacques Silber for drawing our attention to his old but very useful paper, to which we have referred in many places of this paper.

** E-mail address for correspondence: hyun.son@undp-povertycentre.org ; Tel: 55-61-2105 5025;

Fax: 55-61-2105 5000/5001.
} 


\section{INTRODUCTION}

The theory of the cost of living index has been developed to give a precise meaning to price indices that are widely computed to make cost of living comparisons. Many economists have contributed to the development of the theoretical foundation of consumer price indices, the most important contributions being those of Hicks (1946), Pollak (1983, 1998), Diewert (1976, 1990), Samuelson and Swamy (1979) and Konüs (1924).

Most of the literature on the theory of the cost of living index is focused on the comparison of the welfare of a single consumer in different price situations. However, cost of living indices defined for a single consumer do not take into account the effect of price changes on real income inequality, which always exists in the real world. Muellbauer (1974) has shown that the price changes in the United Kingdom since 1974 have had an inequality-increasing bias. He used the Atkinson (1970) inequality index in conjunction with the linear expenditure system to define a real index of expenditure inequality.

To take into account the effect of price changes on income inequality, we need to develop social cost of living indices which are defined for many individuals in the society. An obvious social cost of living index is a simple average of individual cost of living indices. This index is called a democratic price index (Prais 1959, Muellbauer 1974).

The construction of any type of social cost of living index should be derived from a social welfare function which incorporates the value judgements of the society. The democratic cost of living index does not explicitly use a social welfare function. In this paper, we define social cost of living indices in terms of social expenditure functions, which are derived from some specific social welfare functions.

Pollak $(1980,1981)$ proposed a social cost of living index, which is defined as the ratio of the total expenditure required to enable each individual to attain his or her reference indifference curve at comparison prices, to the expenditure required at reference prices. He calls this index a Scitovsky-Laspeyres group cost of living index. Prais (1959) refers to this index as a plutocratic price index. This index has an implicit social welfare function in that it assumes that the society is inequality-neutral in its attitude. This means that the index is completely insensitive to changes in income inequality caused by price changes.

In this paper, we develop the idea of a social expenditure function which forms the basis for defining the true cost of social cost of living indices. This social expenditure is more general than the one suggested by Pollak (1980) and can be made sensitive to changes in inequality caused by changes in relative prices.

The paper derives social cost of living indices on the basis of two alternative classes of social welfare functions. The first class of social welfare functions is utilitarian, according to which every individual has the same utility function. A class of social cost of living indices is derived using a homothetic utility function proposed by Atkinson (1970). The plutonic and democratic social costs of living indices are derived as special cases of this class. ${ }^{1}$

The second class of social cost of living indices is derived from a class of social welfare functions (proposed by Kakwani (1980)) which takes into account the interdependence of individual utilities, i.e., the utility of an individual depends not only on his or her consumption but also on the consumption of others in society. ${ }^{2}$ These indices capture the idea of relative deprivation suffered by individuals with different income levels. 
The most important attribute of the proposed social cost of living indices is that they allow us to choose the degree of inequality aversion in the society. The higher the degree of inequality aversion, the greater the importance the society attaches to income inequality. We compute the social cost of living indices for alternative values of the inequality aversion parameter.

The paper also attempts to provide an intuitive interpretation of inequality aversion parameters based on Okun's (1975) 'leaky bucket' experiment. It shows that Atkinson's social welfare function has much higher tolerance of inefficiency than Kakwani's social welfare function for the same values of the inequality aversion parameter.

Furthermore, the paper derives the explicit relationship between social cost of living indices and aggregate inequality measures. This methodology allowed us to measure the impact of relative price changes on the percentage change in aggregate inequality measures.

Finally, the paper derives the superlative social cost of living indices, which correct for the substitution bias. These indices approximate the true social cost of living index to the second degree approximation in Taylor's expansion. This methodology is basically an extension of Diewert's (1976) superlative indices for a single consumer to price indices for many consumers.

The methodology developed in the paper is applied to compute social cost of living indices for Thailand and Korea. The comparison between these two countries is interesting because they have different levels of inequality, Korea having a much more equal distribution of income than Thailand.

\section{INDIVIDUAL COST OF LIVING INDICES}

Suppose $\mathbf{q}$ is a $n \times 1$ quantity vector, consumption of which provides utility, and which contains everything that is relevant to a representative consumer. We assume that $u(\mathbf{q})$ is the utility level that the consumer can attain if she consumes the consumption vector $\mathbf{q}$. The conventional treatment of consumer behaviour is to maximize the utility function $u(\mathbf{q})$ subject to the constraint $\mathbf{p}^{\prime} \mathbf{q}=\mathrm{x}$, where $\mathbf{p}$ is a column vector of $n$ market prices and $\mathrm{x}$ is income. The solution to this maximization problem yields a system of $n$ Marshallian demand equations $\mathbf{q}=\mathbf{q}(\mathbf{x}, \mathbf{p})$.

Substituting the Marshallian demand equations in the utility function $\mathbf{u}(\mathbf{q})$ and solving for $x$ gives the expenditure function ${ }^{3}$

$$
x=e(u, \mathbf{p})
$$

which is the minimum expenditure that is required in order to obtain utility level $u$ at the price vector $\mathbf{p}{ }^{4}$

Suppose the price vector $\mathbf{p}$ changes to $\mathbf{p}^{*}$, then a true cost of living index will measure the relative cost of buying a given level of utility at the new prices $\mathbf{p}^{*}$ compared to that at the old prices $\mathbf{p}$. The Laspeyres-Konüs index is then defined as (Diewert 1983)

$$
\operatorname{LK}(\mathrm{x})=\frac{\mathrm{e}\left(\mathrm{u}, \mathbf{p}^{*}\right)}{\mathrm{e}(\mathrm{u}, \mathbf{p})}
$$


where $u$ is the base period utility level enjoyed by an individual with income (or total expenditure) $x$.

LK $(x)$ is the true cost of living index of an individual with income $x$. It can be calculated only if we have complete knowledge of the expenditure function. In practice it is difficult to estimate the expenditure function accurately. A practical solution is to assume that the price elasticity of substitution is zero. Using Taylor's expansion, and utilizing the property of the expenditure function that $\frac{\partial \mathrm{e}}{\partial \mathrm{p}_{\mathrm{i}}}=\mathrm{q}_{\mathrm{i}}$, we can write

$$
e(u, \mathbf{p} *)=e(u, \mathbf{p})+\sum_{i}^{n} \frac{\left(p_{i}^{*}-p_{i}\right)}{p_{i}} v_{i}(x)
$$

where $v_{i}(x)=p_{i} q_{i}(x)$ and $q_{i}(x)$ is the consumption of the ith commodity by an individual with income $x$. The terms of the higher order of smallness in (3) have been ignored because of the assumption of zero substitution elasticity. Utilizing (3) into (2), LK(x) index becomes

$$
L(\mathrm{x})=\sum_{i=1}^{n} \frac{p_{i}^{*}}{p_{i}} \eta_{i}(x)=\sum \frac{p_{i}^{*}}{p_{i}} w_{i}(x)
$$

where $\eta_{i}(x)=w_{i}(x)$ is the elasticity of $\mathrm{e}(\mathrm{u}, \mathrm{p})$ with respect to $\mathrm{p}_{\mathrm{i} .}$ and $w_{i}(x)$ is the share of the ith commodity in the consumption of the individual with income $x$. The interpretation of this elasticity is that if the price of the ith commodity increases by 1 percent, the expenditure of individual with income $x$ should increase by $w_{i}(x)$ percent in order to maintain the same level of utility as before the price increase. $L(x)$ is the Laspeyres price index of individual with income $x$, (which is a price index for a single consumer whose income is equal to $x$ ). In the next section, we generalize the idea of price index of a single individual to a price index of the whole society, which consists of many heterogeneous individuals.

\section{SOCIAL COST OF LIVING INDICES}

Suppose $\tilde{\mathrm{u}}$ is the aggregate welfare of the society, obtained by aggregating the levels of utilities enjoyed by the individuals in the society. Then we define the social expenditure function denoted by $e(\tilde{u}, \mathbf{p})$ as the minimum money income which, if given to every individual, will allow the society to enjoy $\tilde{u}$ level of social welfare at a given price vector $\mathbf{p}$. If the price vector $\mathbf{p}$ changes to $\mathbf{p}^{*}$, then every individual should receive the minimum income of $e\left(\tilde{u}, \mathbf{p}^{*}\right)$ in order for the society to enjoy the same level of welfare (as before the price change). 
The social expenditure function should have the following properties:

(i) $e(\tilde{u}, \mathbf{p})$ is an increasing of function $\tilde{\mathrm{u}}$ for all $\mathbf{p}$.

(ii) $e(\tilde{u}, \mathbf{p})$ is increasing and concave in $\mathbf{p}$ for every $\tilde{\mathbf{u}}$.

(iii) $e(\tilde{u}, \mathbf{p})$ is (positively) linearly homogeneous in $\mathbf{p}$ for every $\tilde{\mathbf{u}}$, i.e. $e(\tilde{u}, \lambda \mathbf{p})=\lambda e(\tilde{u}, \mathbf{p})$.

We may now define the true social cost of living index (TSCLI) as

$$
T=\frac{e\left(\tilde{u}, \mathbf{p}^{*}\right)}{e(\tilde{u}, \mathbf{p})}
$$

Note that if all prices increase by the same proportion, i.e., $\mathbf{p}^{*}=\lambda \mathbf{p}$, then T must be equal to $\lambda$. This is a necessary requirement of a price index and is satisfied by $T$ in view of the fact that $e(\tilde{u}, \mathbf{p})$ is (positively) linear homogeneous in $\mathbf{p}$, i.e., $e(\tilde{u}, \lambda \mathbf{p})=\lambda e(\tilde{u}, \mathbf{p})$.

The social expenditure function $e(\tilde{u}, \mathbf{p})$ must be a function of the individual expenditure functions $e(u, \mathbf{p})$ for the three properties given above to be satisfied.

Again assuming that price elasticities of substitution are zero, the true social cost of living index in (5) can be approximately written as

$$
\mathrm{L}=\sum \frac{p_{i}^{*}}{p_{i}} \tilde{\eta}_{i}
$$

where

$$
\tilde{\eta}_{i}=\frac{\partial e(\tilde{u}, p) p_{i}}{\partial p_{i} e(\tilde{u}, p)}
$$

which may be described as the social elasticity, which is the elasticity of $e(\tilde{u}, p)$ with respect to $p_{i}$. The interpretation of this elasticity is that if the price of ith commodity increases by 1 percent, then the minimum money income given to everyone in the society should increase by $\tilde{\eta}_{i}$ percent in order for the society to enjoy the same social welfare as before the price increase. L may be called as Laspeyres Social Cost of Living Index. To make this index operational we need to specify a social welfare function. This is done in the next section.

\section{ATKINSON'S SOCIAL WELFARE FUNCTION}

To derive $e(\tilde{u}, \mathbf{p})$, we utilize the concept of the "equally distributed equivalent level of income" (Atkinson 1970). Thus, $e(\tilde{u}, \mathbf{p})$ may be interpreted as the equally distributed equivalent level of income, the level which, if received by every individual, would result in the same level of social welfare as the present distribution. Like Atkinson, we assume that the social welfare function is utilitarian and that every individual has exactly the same utility 
function. Furthermore, if $g[e(u, \mathbf{p})]$ is the utility enjoyed by an individual whose income in the base period is $\mathrm{x}$ (which is equal to $e(u, \mathbf{p})$ ) where $\mathrm{g}(\mathrm{x})$ is increasing in $\mathrm{x}$ and is concave, then the social welfare function will be

$$
W=\int_{0}^{\infty} g[e(u, \mathbf{p})] f(x) d x
$$

$g[e(\tilde{u}, \mathbf{p})]$ will be the average welfare enjoyed by the society if every individual in it receives an income level of $e(\tilde{u}, \mathbf{p})$. This, obviously, should be equal to $W$ in (8). Thus, we have

$$
g[e(\tilde{u}, \mathbf{p})]=\int_{0}^{\infty} g[e(u, \mathbf{p})] f(x) d x
$$

which gives the relationship between the expenditure functions of individuals in the society and the social expenditure function.

Since $\mathrm{g}^{\prime}(\mathrm{x})>0$ for all $\mathrm{x}$ and $e(u, \mathbf{p})$ is an increasing function of $\mathrm{u}$, the social expenditure function $e(\tilde{u}, \mathbf{p})$ will also be an increasing function of $\tilde{\mathrm{u}}$. Thus, the social expenditure function defined in (8) will satisfy property (i) as given above. Property (ii), the social expenditure function, which is increasing and concave in $\mathbf{p}$, is also satisfied in view of the assumption that $g(x)$ is an increasing and concave function $x$.

The third property, i.e. $e(\tilde{u}, \mathbf{p})$ is (positively) linearly homogeneous in $\mathbf{p}$ for every $\tilde{\mathrm{u}}$, will be satisfied only if it is assumed that $g(x)$ is a homothetic function in $x$. A class of homothetic functions is given by (Atkinson 1970) ${ }^{5}$

$$
\begin{aligned}
g(x) & =A+\frac{B x^{1-\varepsilon}}{1-\varepsilon}, & & \varepsilon \neq 1 \\
& =A+B \log _{e}(x), & \varepsilon & =1
\end{aligned}
$$

where $\varepsilon>0$ is a measure of relative risk-aversion, which is constant for this utility function. Substituting (9) into (8) gives the social expenditure function

$$
\begin{aligned}
e(\tilde{u}, \mathbf{p}) & =\left[\int_{0}^{\infty}\{e(u, \mathbf{p})\}^{1-\varepsilon} f(x) d x\right]^{\frac{1}{1-\varepsilon}}, \quad \text { if } \mathcal{E} \neq 1 \\
& =\exp \left[\int_{0}^{\infty} \log \{e(u, \mathbf{p})\} f(x) d x\right], \quad \text { if } \mathcal{E}=1
\end{aligned}
$$

where 'exp' stands for exponential function. Note that this social expenditure function satisfies the properties (i), (ii), and (iii) as given above. ${ }^{6} \varepsilon$ is called the inequality aversion parameter, which is interpreted as a measure of relative sensitivity to income transfers at different income or expenditure levels. As $\varepsilon$ rises, more and more weight is attached to income transfers at the 
lower end of the distribution and less weight to transfers at the top. If $\varepsilon=0$, it reflects an inequality-neutral attitude, in which case, the society does not care about inequality at all.

The elasticity of $e(\tilde{u}, \mathbf{p})$ given in (10) with respect to $\mathrm{p}_{\mathrm{i}}$ is given by

$$
\tilde{\eta}_{i}(\varepsilon)=\frac{\int_{0}^{\infty} w_{i}(x) x^{(1-\varepsilon)} f(x) d x}{\int_{0}^{\infty} x^{(1-\varepsilon)} f(x) d x}
$$

Substituting (11) into (6) gives a class of Laspeyres Social Cost of Living Indices:

$$
L(\varepsilon)=\sum_{1}^{n} \frac{p_{i}^{*}}{p_{i}} \tilde{\eta}_{i}(\varepsilon)
$$

Let us now consider different members of this class. Substituting $\varepsilon=0$ in (12) gives

$$
\mathrm{L}(0)=\sum \frac{p_{i}^{*}}{p_{i}} \bar{w}_{i}
$$

where

$$
\bar{w}_{i}=\frac{\int_{0}^{\infty} w_{i}(x) x f(x) d x}{\int_{0}^{\infty} x f(x) d x}
$$

is the average budget share of the ith commodity. It is calculated as the weighted average of individual budget shares, where weights are the fraction of aggregate income held by each individual. The rich are given greater weight than the poor in the measurement of inflation and therefore Prais (1959) called it a Plutonic Cost of Living Index. This index is neutral to any change in relative inequality because changes in prices affect every individual proportionally to his or her income. This index, popularly known as Laspeyres index, does not tell us whether or not the price changes hurt the poor proportionally more than the rich. Almost all countries in the world use this index to measure their inflation rate.

Substituting $\varepsilon=1$ in (12) gives

$$
\mathrm{L}(1)=\sum \frac{p_{i}^{*}}{p_{i}} \tilde{w}_{i}
$$


where

$$
\tilde{\mathrm{w}}_{\mathrm{i}}=\int_{0}^{\infty} \mathrm{w}_{\mathrm{i}}(\mathrm{x}) \mathrm{f}(\mathrm{x}) \mathrm{dx}
$$

is the average of the individual budget shares of the society. Since every individual gets the same weight irrespective of income, Prais (1959) called this index the Democratic Cost of Living Index.

It will be instructive to write

$$
L(1)=L(0)+\sum_{i=1}^{n} \frac{p_{i}^{*}}{p_{i}}\left(\tilde{w}_{i}-\bar{w}_{i}\right)
$$

where $\overline{\mathrm{w}}_{\mathrm{i}}$ is the ith commodity budget share of an average consumer in the society. $\overline{\mathrm{w}}_{\mathrm{i}}$ will generally be different from $\widetilde{w}_{i}$. If the ith commodity is a necessary good such as food, $\bar{w}_{i}(x)$ will be higher for the poor than for the non-poor. For such commodities, therefore, $\tilde{\mathrm{w}}_{\mathrm{i}}>\overline{\mathrm{w}}_{\mathrm{i}}$. If the ith commodity, however, is a luxury good, then $\widetilde{\mathrm{w}}_{\mathrm{i}}<\overline{\mathrm{w}}_{\mathrm{i}}$. The second term in (16) will be positive (negative) if the prices of necessary (luxury) goods increase at a faster rate than the prices of luxury (necessary) goods. Thus, this term indicates whether price changes hurt the poor more than the rich. If $L(1)-L(0)$ is positive (negative), changes in prices hurt the poor (rich) more than the rich (poor), which implies that $L(1)$ is sensitive to the changes in real inequality in the society as a result of relative price changes.

As $\mathcal{E}$ increases to infinity, Laspeyres Social Cost of Living Indices in (12) will be given by

$$
L(\infty)=\sum_{i=1}^{n}\left(\frac{p_{i}^{*}}{p_{i}}\right) w_{i p}
$$

where $w_{\text {ip }}$ is the budget share of the poorest person in the society. This index will be used if the society is only concerned with the welfare of the poorest person in the society. This index is consistent with Rawls' theory of justice, which gives all the weight to the worst-off person in the society. This may be regarded as an extreme situation. In practice, $\varepsilon=2$ will probably provide a reasonable social cost of living index. Nonetheless, we emphasize that the choice of $\varepsilon$ depends on the kind of society for which the index is computed. If a society has a high degree of inequality, then a higher value of $\varepsilon$ may be considered to be more appropriate. ${ }^{8}$

\section{SOCIAL COST OF LIVING INDICES WHEN SOCIAL WELFARE FUNCTION IS INTERDEPENDENT}

In the previous section we derived social cost of living indices from a class of social welfare functions in which the utility or welfare of an individual depended only on his or her own income or consumption. In this section we derive a class of social cost of living indices which takes into account the interdependence of individual utilities. The utility of an individual depends not only on his or her income but also on the incomes of others in the society. Such a 
social welfare function captures the idea of relative deprivation suffered by individuals with different income levels; the lower a person is on the welfare scale, the greater is his or her sense of deprivation with respect to others in the society.

Sen (1974) proposed a social welfare function which, by taking into account the proportion of persons who are richer, captures the relative deprivation suffered by individuals. Kakwani (1980) proposed a generalization of Sen's social welfare function, which allows a judgement to be made about the society's degree of aversion to inequality. The social expenditure function based on this social welfare function may be defined as

$$
e(\tilde{u}, \mathbf{p})=(k+1) \int_{0}^{\infty} e(u, \mathbf{p})[1-F(x)]^{k} f(x) d x
$$

where $\mathrm{F}(\mathrm{x})$ is the distribution function and is the proportion of people in the society who have income less than or equal to $\mathrm{x}$. Elasticity of $e(\tilde{u}, p)$ with respect to $\mathrm{p}_{\mathrm{i}}$ is obtained as

$$
\tilde{\eta}_{i}^{*}(k)=\frac{\int_{0}^{\infty} w_{i}(x) x[1-F(x)]^{k} f(x) d x}{\int_{0}^{\infty} x[1-F(x)]^{k} f(x) d x}
$$

which, on substituting in (6), gives a class of social cost of living indices as

$$
L^{*}(k)=\sum \frac{p_{i}^{*}}{p_{i}} \tilde{\eta}_{i}^{*}(k)
$$

The parameter $k$ can be interpreted as a measure of inequality aversion. In particular, $k=0$ implies an inequality-neutral attitude for the society. For $k=0, L^{*}(k)$ is equal to $L(0)$ as given in (13). It can easily be demonstrated (Kakwani 1980) that

$$
2 \int_{0}^{\infty} x[1-F(x)] f(x) d x=\mu(1-G)
$$

and that

$$
2 \int_{0}^{\infty} v_{i}(x)[1-F(x)] f(x) d x=\mu_{i}\left(1-C_{i}\right)
$$

where $\mu$ is the mean income of the society and $G$ is the Gini index, which is a well-known measure of inequality, $\mathrm{v}_{\mathrm{i}}(\mathrm{x})=\mathrm{p}_{\mathrm{i}} \mathrm{q}_{\mathrm{i}}(\mathrm{x})$ is the expenditure of a person with income $\mathrm{x}$ on the ith commodity at the base year price, $\mu_{\mathrm{i}}$ is the mean expenditure of the society on the ith commodity and $C_{i}$ is the concentration index of the ith commodity. ${ }^{9}$ 
Let us now substitute $k=1$ into (20) and utilizing (19) we obtain

$$
L *(1)=L(0)-\frac{1}{(1-G)} \sum_{i=1}^{n} \frac{p_{i}^{*}}{p_{i}} \bar{w}_{i} E_{i}
$$

where $E_{i}=C_{i}-G$.

$E_{i}=C_{i}-G$ is the elasticity index proposed by Kakwani (1980). The ith commodity is luxury (necessity) if $E_{i}$ is greater (less) than zero. If the prices of necessities (luxuries) increase faster than those of luxuries (necessities), the second term in (20) will be positive (negative). Thus, the sign of the second term in (23) tells us whether or not the price changes have a relatively larger adverse impact on the poor.

The social cost of living index $K^{*}(k)$ can be computed for any value of $k$. The larger the value of $k$ we choose, the greater is our concern for the poor.

\section{IMPACT OF PRICE CHANGE ON INEQUALITY}

As noted in the previous sections, the social cost of living indices provide the means to assess whether price changes have an adverse impact on the poor or the non-poor (or how price changes affect aggregate inequality in a society). In this section, we derive the explicit relationship between the social cost of living indices and change in the aggregate inequality.

Following Atkinson (1970), inequality in the society is defined as

$$
I_{A}=1-\frac{e(\tilde{u}, \mathbf{p})}{\mu(\mathbf{p})}
$$

where

$$
\mu(\mathbf{p})=\int_{0}^{\infty} e(u, \mathbf{p}) f(x) d x
$$

is the mean income of the society in the base period and $e(\tilde{u}, \mathbf{p})$ is a monetary measure of the society's standard of living in the base period.

Suppose the price vector $\mathbf{p}$ changes to $\mathbf{p}^{*}$ in the next period, then $e\left(\tilde{u}, \mathbf{p}^{*}\right)$ will be the social expenditure per person in order for the society to enjoy the same level of social welfare $\tilde{u}$ (as in the base period). The inequality after the price change will be given by

$$
I_{A}^{*}=1-\frac{e\left(\tilde{u}, p^{*}\right)}{\mu\left(p^{*}\right)}
$$


where

$$
\mu\left(\mathbf{p}^{*}\right)=\int_{0}^{\infty} e\left(u, \mathbf{p}^{*}\right) f(x) d x
$$

Using (25) and (26) in (5) gives

$$
T=\frac{\mu\left(\mathbf{p}^{*}\right)}{\mu(\mathbf{p})}+\frac{\mu\left(p^{*}\right)\left(I_{A}^{*}-I_{A}\right)}{\mu(p)\left(1-I_{A}\right)}
$$

where $T$ is the true social cost of living index as defined in (5). Note that the first term on the right hand side is the Scitovsky-Laspeyres Social Cost of Living Index as proposed by Pollak(1981). This index is neutral to any change in inequality. The second term on the right hand side of (27) measures the distributional impact of price change. This term is positive if changes in prices increase aggregate inequality, and will be negative if price changes reduce inequality in the society. If we assume that substitution bias is zero, the impact of prices on Atkinson's inequality measures will be given by

$$
\frac{I_{A}^{*}(\varepsilon)-I_{A}(\varepsilon)}{I_{A}(\varepsilon)}=\frac{[L(\varepsilon)-L(0)]\left[1-I_{A}(\varepsilon)\right]}{L(0) I_{A}(\varepsilon)}
$$

which allows us to compute the percentage change in inequality as a consequence of changes in prices.

\section{SUBSTITUTION BIAS}

The social costs of living indices have been defined in terms of individual expenditure functions. To make these indices operational, we assumed that price elasticity of substitution is zero for all consumers. In doing so, we have been assuming that no consumer substitution occurs in response to changes in relative prices. Although this assumption is overly restrictive, there exists no easy way to deal with this issue in practical situations.

One obvious method that deals with the issue is to estimate the expenditure function for each consumer by utilizing an estimated system of demand equations (Braithwait, 1980, Jorgenson and Slesnick, 1983). This method can be implemented with a reasonable degree of accuracy only for a small number of broad commodity groups. Since the number of parameters to be estimated in a full system of consumer demand rises with the square of (one less than) the number of commodities, the method becomes impossible to implement at any detailed level of commodity disaggregation (Boskin, Dulberger, Gordon, Griliches and Jorgenson 1998). Moreover, this method would become even more difficult to implement when we are attempting to estimate the social cost of living indices, which would involve estimating the substitution bias for each of many consumers.

A more attractive alternative is to use superlative indices, pioneered by Diewert (1976). These indices approximate the true cost of living index to the second degree without requiring 
econometrics for implementation. An extension of this approach to social costs of living is discussed in this section.

The Laspeyres-Konus index $\operatorname{LK}(\mathrm{x})$ in (2) was approximated by the Laspeyres index $\mathrm{L}(\mathrm{x})$ by utilizing the first term in the Taylor's expansion. To take into account the substitution bias we have to utilize the second degree approximation in the Taylor's expansion. It can be easily shown that

$$
\log \left[e\left(u, p^{*}\right)\right]=\log [e(u, p)]+\frac{1}{2} \sum_{1}^{n}\left(\log p_{i}^{*}-\log \left(p_{i}\right)\left[\eta_{i}(x)+\eta_{i}^{*}(x)\right]\right.
$$

where $\eta_{i}(x)$ and $\eta_{i}^{*}(x)$ are the elasticities of base and terminal individual expenditure functions with respect to the price of the ith commodity in the base and terminal years, respectively. Substituting (29) into (2), we obtain the second order approximation of the Laspeyres-Konus index for an individual with income $x$ as

$$
T^{*}(x)=\exp \left[\frac{1}{2} \sum_{1}^{n}\left[\log \left(p_{i}^{*}\right)-\log \left(p_{i}\right)\right]\left[\eta_{i}(x)+\eta_{i}^{*}(x)\right]\right.
$$

The social cost of living index can be derived from (30) if we substitute the elasticities of the individual expenditure functions by the elasticities of the social expenditure functions. Thus we have a new social cost of living index

$$
T^{*}=\exp \left[\frac{1}{2} \sum_{1}^{n}\left[\log \left(p_{i}^{*}\right)-\log \left(p_{i}\right)\right]\left[\tilde{\eta}_{i}+\tilde{\eta}_{i}^{*}\right]\right.
$$

where

$$
\tilde{\eta}_{i}=\frac{\partial e(\tilde{u}, p) p_{i}}{\partial p_{i} e(\tilde{u}, p)} \quad \text { and } \quad \tilde{\eta}_{i}^{*}=\frac{\partial e\left(\tilde{u}^{*}, p^{*}\right) p_{i}^{*}}{\partial p_{i}^{*} e\left(\tilde{u}^{*}, p^{*}\right)}
$$

These elasticities can be computed for both Atkinson and Kakwani classes of social welfare functions (see equations (11) and (19)). The social cost of living indices so obtained will take account of substitution biased at least up to the second order approximation. To be able to implement this methodology we need to have at least two household surveys in order to calculate these elasticities in the base and terminal years.

\section{8 'LEAKY BUCKET'10}

In this paper we have developed the social costs of living indices utilizing two major classes of social welfare functions, namely, Atkinson's and Kakwani's. In Atkinson's social welfare function, the utility of an individual depends only on her own consumption, whereas in Kakwani's social welfare function the utility of an individual depends not only on her own consumption but also on how many persons in the relevant society have higher consumption than her. It is difficult to make a recommendation about the choice between the two classes of 
social welfare functions. Since Kakwani's function captures the idea of relative deprivation suffered by individuals with different income levels, some policy-makers may find it a more attractive choice. However, even if we agree on the functional form, it is far more difficult to arrive at an agreement on the value of inequality aversion parameter; $\mathcal{E}$ for Atkinson's and $k$ for Kakwani's. We only know from both functions that, as an inequality aversion parameter increases, the greater weight is given to incomes at the lower end of the income distribution. A society which has a higher aversion to inequality will choose a higher value of the inequality aversion parameter. ${ }^{11}$ This information is not sufficient to be able to choose a single value of either $\varepsilon$ or $k$.

We attempt to motivate the choice based on Okun's (1975) 'leaky bucket' experiment. Imagine a hypothetical society consisting of two persons: one is poorer than the other and their incomes are $\$ 50$ and $\$ 500$, respectively. To have a grasp of welfare in this society we might think of a function where total welfare increases whenever the incomes of these two persons grow and whenever the increase in income of one individual does not decrease the income of the other. This is the famous Pareto optimality criterion. We may introduce the second property to this function to state that any transfer of income from rich to poor increases social welfare. This is called the Pigou-Dalton principle of transfer. The basic idea behind this principle is that the gain of $\$ 1$ by the poor is more valuable to the society than the loss of $\$ 1$ to the rich. Taken all together, these criteria imply that any redistribution of income from rich to poor will increase the social welfare, provided that total income available to the society does not decrease.

Since the consumption patterns of the poor and rich are different, any change in relative prices will change the real distribution of income in favour of either the poor or the rich. A change in relative prices is equivalent to transferring incomes between the poor and the rich. For instance, if the government subsidises commodities that are consumed by the poor, it is basically transferring income from the rich to the poor. Thus, the main motive of constructing social cost of living indices is to capture the impact of changes in relative prices on the living standard of the poor.

It must be pointed out that there is no costless transfer of money from the rich to the poor. The money must be carried from the rich to the poor in a leaky bucket (Okun, 1975): some of the money will always disappear in transit so the poor will not receive all the money that is taken from the rich. The leakage basically represents inefficiency. The issue is: how much inefficiency should a society tolerate? The answer is provided by the value of inequality aversion chosen by the society: the higher the value of the inequality aversion parameter, the greater the society's tolerance for inefficiency. Thus, the percentage leakage is a monotonically increasing function of the inequality aversion parameter.

To illustrate how the two types of social welfare functions interplay with leakages, let us suppose we transfer $\$ 25$ (5 percent of the income of the rich) from the rich to the poor, but that the poor will get less than $\$ 25$ depending on how much the leakage is. The transfer will stop at the point when social welfare becomes negative (when transfer becomes undesirable). Table 1 presents the percentage of leakage when change in social welfare becomes negative and total welfare is reduced. We call this as tolerable level of leakage, which varies with values of inequality aversion parameter. 
TABLE 1

Percentage of tolerable leakage

\begin{tabular}{ccc}
\hline Inequality aversion parameter & Atkinson's welfare function & Kakwani's welfare function \\
\hline 0 & 0 & 0 \\
0.5 & 66.5 & 30.0 \\
1.0 & 89.5 & 50.0 \\
1.5 & 96.5 & 65.0 \\
2.0 & 99.0 & 75.0 \\
3.0 & 99.9 & 87.5 \\
\hline
\end{tabular}

\section{FIGURE 1}

Percentage of tolerable leakage implied by Atkinson's and Kakwani's social welfare function

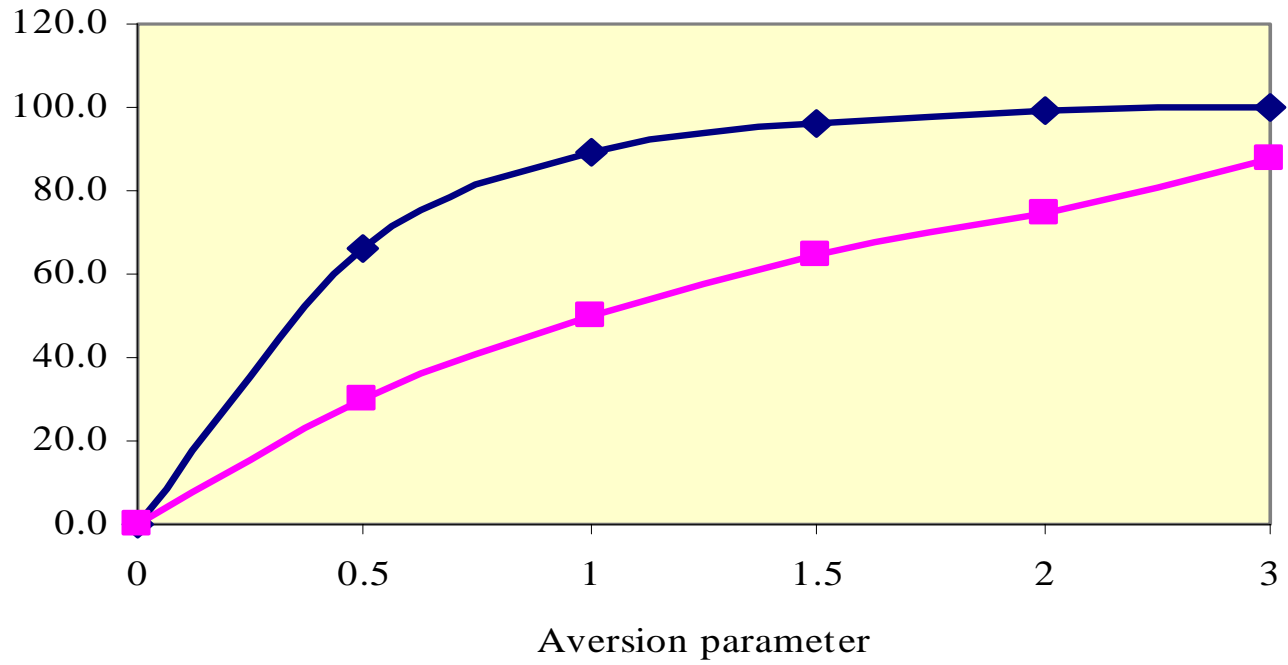

Atkinson's Kakwani's

In the case of Atkinson's social welfare function when $\varepsilon=1$, the tolerable leakage is 89.5 percent. In other words, we would be willing to waste about 90 percent of the amount before we regard the transfer as undesirable. When $\varepsilon=2$, the tolerable leakage is as high as 99 percent. In the case of Kakwani's social welfare function, the tolerable leakage is 50 percent when $k=1$ (which is the welfare function implied by the Gini index). Figure 1 shows that Atkinson's social welfare gives a much higher tolerance level than Kakwani's social welfare function at each value of inequality aversion parameter. Thus, the society behaving along the lines of an Atkinson's social welfare function is much more concerned with inequality than a society behaving according to Kakwani's social welfare function for the same value of inequality aversion parameter.

Although we have not provided a clear-cut answer to the question as to what value of inequality aversion parameter we should choose, the above intuitive interpretation of inequality aversion parameters may help in making this choice. 


\section{IMPLEMENTATION OF METHODOLOGY}

To implement the methodology discussed in the previous sections, we require two data sources. One is the household expenditure surveys, which provide detailed expenditures of each household in monetary terms, and the other is the average market prices of various items of consumption. It is important that market prices of individual items of consumption must match with expenditure categories given in the household surveys.

To estimate the social elasticities accurately from the sample households, we need to know the weight attached to each sampled household to enable the data provided by these households to be expanded to obtain estimates for the defined population. For instance, if $M$ is the number of households in the population and $\mathrm{m}$ is the sample of households selected in the survey, then the weight attached to every household will be $\mathrm{M} / \mathrm{m}$. This weight is not correct because it is based on the assumption that every household in the population has exactly the same probability of being selected. The weight given to each household must be determined by the probability of selection within a stratum adjusted to take account of non-responding households. These weights are estimated using the sample design used in the survey. Most of the household surveys provide these weights. These weights are called household weights because they sum up to the total number of households in the population.

Since we are interested in the welfare of individuals, we must obtain the individual weights, which can be obtained by multiplying the household weights by the household size. These individual weights may be called population weights because they sum up to the total population in the country. Suppose $P_{\mathrm{j}}$ is the population weight of the jth sample household, then

$$
a_{j}=\frac{P_{j}}{\sum_{1}^{m} P_{j}}
$$

will be the share of total population represented by the jth sample household so that

$$
\sum_{1}^{m} a_{j}=1
$$

Suppose total household consumption consists of $n$ individual items of consumption and the prices of each of these items are given from market surveys in the base and terminal years, then we can estimate Atkinson's class of social cost of living indices from (12) if we know the social elasticity $\tilde{\eta}_{i}(\varepsilon)$ for each item of consumption.

Suppose $x_{i j}$ is the per capita consumption of the ith item by the jth household and $x_{j}$ is the per capita total consumption of the jth household, then the budget share of the ith item by the jth household will be given by $w_{i j}=\frac{x_{i j}}{x_{j}}$, where $\sum_{i=1}^{n} w_{i j}=1$ for all $\mathrm{j}=1,2, \ldots, m$. The social elasticity for the Atkinson's class of social welfare functions can then be estimated as 


$$
\tilde{\eta}_{i}(\varepsilon)=\frac{\sum_{j=1}^{m} a_{j} w_{i j} x_{j}^{(1-\varepsilon)}}{\sum_{j=1}^{m} a_{j} x_{j}^{(1-\varepsilon)}}
$$

To compute social welfare elasticity for Kakwani's class of social welfare functions, we need to estimate the probability distribution function $F(x)$ from the discrete data so that we have apply a continuity correction. An unbiased estimate of $F\left(x_{j}\right)$ is given by

$$
r_{j}=\sum_{l=1}^{j} a_{l}-\frac{a_{j}}{2}
$$

so that $\sum_{j=1}^{m} a_{j} r_{j}=\frac{1}{2}$. Then social elasticity for Kakwani's class of social welfare functions is estimated using (19) by

$$
\tilde{\eta}_{i}(k)=\frac{\sum_{j=1}^{m} a_{j} w_{i j} x_{j}\left(1-r_{j}\right)^{k}}{\sum_{j=1}^{m} a_{j} x_{j}\left(1-r_{j}\right)^{k}}
$$

Substituting this elasticity in (20) gives Kakwani's class of social cost of living indices. ${ }^{12}$

The methodology presented here can be applied to any specific demographic groups such as the elderly and children, who have different consumption patterns from the general population. For instance, elderly people have to spend a greater share of their total expenditure on health care, whereas families with children usually spend more on education. Within these groups also there are both poor and rich households, which have different expenditure patterns. To take account of these differences, we could compute group cost of living indices using the methodology presented in this paper. ${ }^{13}$

These indices can play an important role in maintaining the standard of living of vulnerable groups, such as the elderly and children.

In the above methodology, we have used per capita total expenditure as a measure of household welfare. This is an approximate measure of household welfare because it assumes that the basic needs of every household member are the same irrespective of their age and sex. Furthermore, the larger households enjoy economies of scale, which can further bias the empirical results. The methodology presented here can be easily modified to take account of these refinements by utilizing adult equivalence scale and economies of scale parameter (Deaton 1998). We did not follow this path because we did not have credible estimates of equivalence scale and economies scale parameters. 


\section{SOCIAL COST OF LIVING INDICES FOR THAILAND}

In this section, we use the methodology developed in this paper to compute the social cost of living indices for Thailand. The indices were computed annually, covering the period from 1986 to 1995 . The social weights developed in the paper were computed using the Socioeconomic Survey (SES) data for 1990. The price indices of various goods and services were obtained from the Department of Business Economics of the Ministry of Commerce in Bangkok, Thailand.

The National Statistical Office (NSO) of Thailand conducts the country's Socio-economic Survey on a regular basis. The surveys cover all private non-institutional households residing permanently in municipal areas, sanitary districts and villages. However, they exclude that part of the population living in transient hotels, rooming houses, boarding schools, military barracks, temples, hospitals, prisons and other institutions (see Report of the 1990 Household Socio-economic Survey, NSO, Thailand).

The NSO Thailand provided us with unit record data giving expenditures on a wide variety of goods and services for 13,186 households. Since we could obtain a very detailed disaggregation of goods and sources, the matching of the data from the two sources was not a problem.

The social cost of living indices and inflation rates are presented in Tables 2 and 3 for different values of inequality aversion parameters. Table 2 is based on the utilitarian social welfare function, whereas Table 3 is computed on the basis of the interdependent social welfare function.

It may be recalled that when the inequality aversion parameter is zero, the society is completely inequality-neutral. The higher the inequality aversion parameter, the greater the importance society attaches to inequality. It can be seen that the inflation rate from Table 2 in the $1987-88$ period is 3.8 per cent when the inequality aversion parameter is equal to zero. When the inequality aversion parameter is equal to 2.0 , the inflation rate is 5.2 per cent. This means that during the 1987-88 period, price changes in affected the poor much more than the rich. Consequently, real inequality in the society increased as a result of price changes.

TABLE 2

Price indices and inflation rates in Thailand

\begin{tabular}{|c|c|c|c|c|c|c|c|c|c|c|}
\hline \multirow{3}{*}{ Years } & \multicolumn{10}{|c|}{ Based on Atkinson's social welfare function } \\
\hline & \multicolumn{5}{|c|}{$\begin{array}{l}\text { Social Cost Living Index }(1986=100) \\
\text { When inequality aversion parameter }(\mathcal{E}) \\
\text { is equal to }\end{array}$} & \multicolumn{5}{|c|}{$\begin{array}{c}\text { Annual Inflation rate } \\
\text { When inequality aversion parameter }(\varepsilon) \\
\text { is equal to }\end{array}$} \\
\hline & 0 & 0.5 & 1 & 1.5 & 2 & 0 & 0.5 & 1 & 1.5 & 2 \\
\hline 1986 & 100 & 100 & 100 & 100 & 100 & - & - & - & - & - \\
\hline 1987 & 102.4 & 102.5 & 102.5 & 102.6 & 102.6 & 2.4 & 2.5 & 2.5 & 2.6 & 2.6 \\
\hline 1988 & 106.3 & 106.8 & 107.2 & 107.6 & 107.9 & 3.8 & 4.2 & 4.5 & 4.9 & 5.2 \\
\hline 1989 & 110.7 & 111.5 & 112.1 & 112.6 & 113.0 & 4.2 & 4.4 & 4.6 & 4.7 & 4.7 \\
\hline 1990 & 116.4 & 117.2 & 117.7 & 118.2 & 118.5 & 5.1 & 5.1 & 5.0 & 5.0 & 4.9 \\
\hline 1991 & 122.8 & 123.5 & 124.1 & 124.5 & 124.9 & 5.5 & 5.4 & 5.4 & 5.4 & 5.3 \\
\hline 1992 & 127.4 & 128.3 & 128.9 & 129.4 & 129.7 & 3.8 & 3.9 & 3.9 & 3.9 & 3.9 \\
\hline 1993 & 131.9 & 132.3 & 132.6 & 132.7 & 132.9 & 3.5 & 3.2 & 2.8 & 2.6 & 2.4 \\
\hline 1994 & 137.4 & 138.1 & 138.4 & 138.6 & 138.7 & 4.2 & 4.4 & 4.4 & 4.4 & 4.4 \\
\hline 1995 & 144.3 & 145.3 & 145.8 & 146.1 & 146.2 & 5.0 & 5.2 & 5.3 & 5.4 & 5.4 \\
\hline
\end{tabular}

Source: Authors' calculation. 
FIGURE 2

\section{Inflation rates in Thailand}

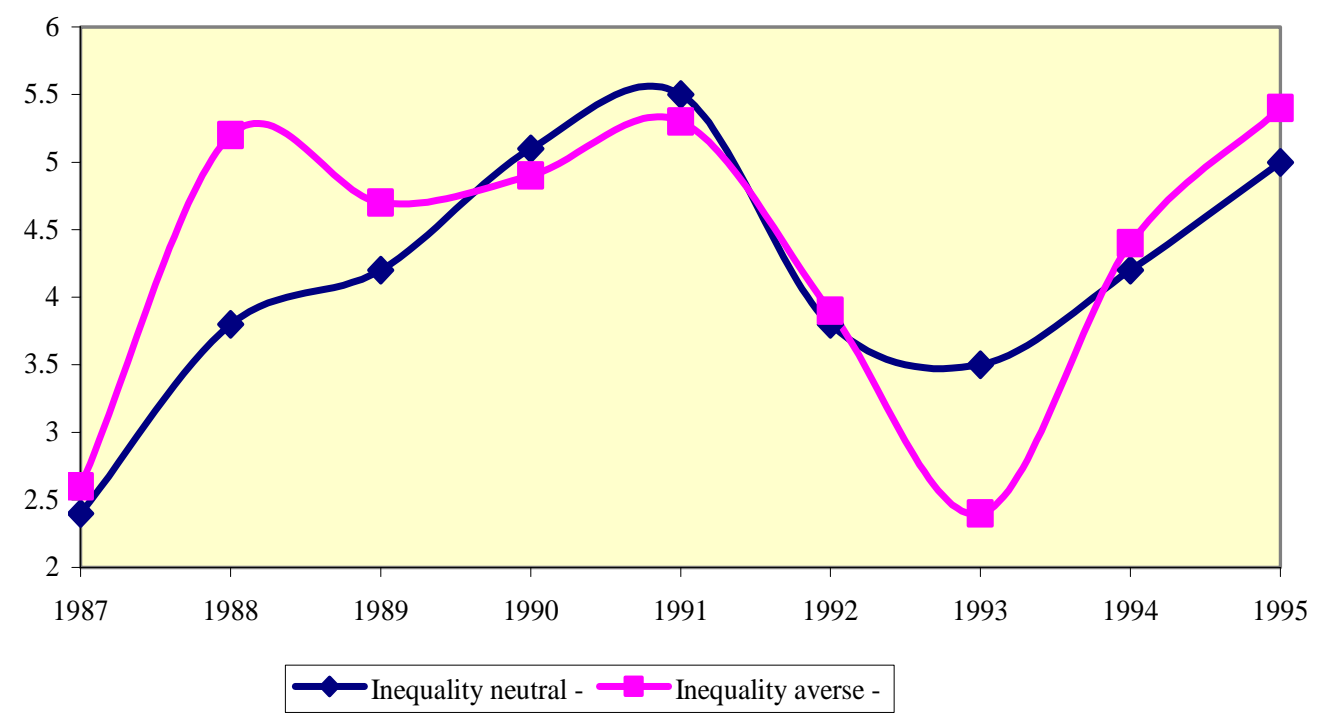

If we look at the entire period from 1986 to 1995, we find that the overall price index increased by 44.3 per cent when the inequality aversion parameter is equal to zero but when it takes a value equal to 2 , the prices increased by 46.2 per cent. This means that price changes in the 1986 - 1995 period favoured the rich more than the poor (Table 2).

Table 3, based on the interdependent social welfare function, shows much larger adverse effects of price changes on the poor. When $\mathrm{k}=3.0$ the index increased by 48.4 per cent between 1986 and 1995 whereas when $k=0$, the increase is only 44.3 per cent. This means that an inflation rate of 4.1 per cent is attributed to inequality increasing the bias of price changes.

TABLE 3

Social cost of living index estimated based on interdependent social welfare

\begin{tabular}{|c|c|c|c|c|c|c|c|c|}
\hline \multirow{3}{*}{ Years } & \multicolumn{8}{|c|}{ Based on interdependent social welfare function } \\
\hline & \multicolumn{4}{|c|}{$\begin{array}{c}\text { Social Cost Living Index }(1986=100) \\
\text { when inequality aversion parameter }(k) \\
\text { is equal to }\end{array}$} & \multicolumn{4}{|c|}{$\begin{array}{c}\text { Annual Inflation rate } \\
\text { when inequality aversion parameter }(k) \\
\text { is equal to }\end{array}$} \\
\hline & 0 & 1 & 2 & 3 & 0 & 1 & 2 & 3 \\
\hline 1986 & 100 & 100 & 100 & 100 & - & - & - & - \\
\hline 1987 & 102.4 & 102.6 & 102.6 & 102.6 & 2.4 & 2.6 & 2.6 & 2.6 \\
\hline 1988 & 106.3 & 107.3 & 107.9 & 108.2 & 3.8 & 4.6 & 5.1 & 5.4 \\
\hline 1989 & 110.7 & 112.3 & 113.1 & 113.5 & 4.2 & 4.7 & 4.8 & 4.9 \\
\hline 1990 & 116.4 & 118.0 & 118.7 & 119.1 & 5.1 & 5.1 & 5.0 & 4.9 \\
\hline 1991 & 122.8 & 124.5 & 125.3 & 125.8 & 5.5 & 5.5 & 5.6 & 5.6 \\
\hline 1992 & 127.4 & 129.5 & 130.4 & 130.9 & 3.8 & 4.0 & 4.1 & 4.1 \\
\hline 1993 & 131.9 & 133.0 & 133.5 & 133.8 & 3.5 & 2.8 & 2.4 & 2.2 \\
\hline 1994 & 137.4 & 139.2 & 139.7 & 140.1 & 4.2 & 4.6 & 4.7 & 4.7 \\
\hline 1995 & 144.3 & 147.0 & 147.8 & 148.4 & 5.0 & 5.6 & 5.8 & 5.9 \\
\hline
\end{tabular}

Source: Authors' calculations.

Next, we want to know the impact of price changes on inequality. Inequality can be measured in many ways depending on what social welfare function is assumed. If we assume the class of 
interdependent social welfare functions, then the inequality measure will vary with the inequality aversion parameter $k$; the larger the inequality aversion parameter, the greater is the weight attached to poor individuals in the society. When $k=1$, the inequality measure is the well-known Gini index. Table 4 presents the values of inequality measures for different values of $k$. The values in 1990 are the actual values of inequality measures as calculated from the 1990 Socio-economic Survey data. The values in other years are the real values of inequality measures, which take account of relative price changes.

TABLE 4

Impact of prices on inequality in Thailand

\begin{tabular}{|c|c|c|c|c|c|c|}
\hline \multirow{3}{*}{ Years } & \multicolumn{6}{|c|}{ Based on interdependent social welfare function } \\
\hline & \multicolumn{3}{|c|}{$\begin{array}{c}\text { Inequality measures } \\
\text { when inequality aversion parameter }(k) \\
\text { is equal to }\end{array}$} & \multicolumn{3}{|c|}{$\begin{array}{l}\text { Annual percentage change in inequality } \\
\text { when inequality aversion parameter }(k) \\
\text { is equal to }\end{array}$} \\
\hline & $1^{*}$ & 2 & 3 & 1 & 2 & 3 \\
\hline 1986 & 49.8 & 49.8 & 49.8 & - & - & - \\
\hline 1987 & 49.9 & 49.9 & 49.9 & 0.2 & 0.3 & 0.3 \\
\hline 1988 & 50.4 & 50.7 & 50.9 & 1.0 & 1.5 & 1.8 \\
\hline 1989 & 50.7 & 51.1 & 51.4 & 0.6 & 0.9 & 1.0 \\
\hline 1990 & 49.8 & 49.8 & 49.8 & -1.8 & -2.5 & -3.0 \\
\hline 1991 & 50.9 & 51.5 & 51.8 & 2.3 & 3.3 & 3.9 \\
\hline 1992 & 51.2 & 51.9 & 52.3 & 0.6 & 0.8 & 1.0 \\
\hline 1993 & 50.6 & 51.0 & 51.2 & -1.2 & -1.7 & -2.0 \\
\hline 1994 & 51.2 & 51.7 & 52.0 & 1.1 & 1.3 & 1.4 \\
\hline 1995 & 52.2 & 53.0 & 53.5 & 2.0 & 2.6 & 2.9 \\
\hline 1986-95 & - & - & - & 4.8 & 6.4 & 7.3 \\
\hline
\end{tabular}

* is the Gini index.

Source: Authors' calculations.

It is noted that from Table 4 that annual increases in prices have generally increased inequality every year except in 1989-90 and 1992-93. If we look at the entire period from 1986 to 1995 , we find that price changes had the effect of increasing inequality. For instance, the inequality measure for $k=1$, which is the Gini index, increased by 4.8 percent due to changes in relative prices between 1986 and 1995 . Thus, the poor were adversely affected by price changes. It is interesting that when $k=3$, the percentage increase in inequality is 7.3 percent, which means that we give greater weight to the poor, the increase in inequality is higher. This implies that the ultra-poor have been more adversely affected than the poor due to changes in relative prices. ${ }^{14}$

\section{SOCIAL COSTS OF LIVING INDICES FOR KOREA}

In this section, we compute the social costs of living indices for Korea. Korea is an interesting case because it has maintained a much more equal distribution of income than Thailand. Moreover, Korea conducts the Family Income and Expenditure (FIAE) surveys every year, so it is possible to compute superlative indices discussed in Section 7.

We computed the social costs of living indices annually covering the period from 1990 to 1999. Tables 5 and 6 give the social costs of living indices based on the Atkinson and interdependent classes of social welfare functions. The social elasticities were computed using the 1990 Family Income and Expenditure Survey. The estimates of social costs of living indices given in these tables do not take account of substitution bias and are based on fixed social weights prevailing in 1990. 
TABLE 5

Social cost of living indices and inflation rates in Korea

\begin{tabular}{|c|c|c|c|c|c|c|c|c|}
\hline \multirow{3}{*}{ Years } & \multicolumn{8}{|c|}{ Based on Atkinson's social welfare function } \\
\hline & \multicolumn{4}{|c|}{$\begin{array}{c}\text { Social Cost Living Index }(1990=100) \\
\text { when inequality aversion parameter }(k) \\
\text { is equal to }\end{array}$} & \multicolumn{4}{|c|}{$\begin{array}{c}\text { Annual Inflation rate } \\
\text { when inequality aversion parameter }(k) \\
\text { is equal to }\end{array}$} \\
\hline & 0 & 1 & 2 & 3 & 0 & 1 & 2 & 3 \\
\hline 1990 & 100.0 & 100.0 & 100.0 & 100.0 & - & - & - & - \\
\hline 1991 & 108.7 & 108.9 & 109.1 & 109.2 & 8.7 & 8.9 & 9.1 & 9.2 \\
\hline 1992 & 114.9 & 115.1 & 115.3 & 115.5 & 5.7 & 5.7 & 5.7 & 5.7 \\
\hline 1993 & 120.1 & 120.2 & 120.4 & 120.5 & 4.5 & 4.5 & 4.4 & 4.4 \\
\hline 1994 & 128.0 & 128.3 & 128.6 & 128.8 & 6.6 & 6.7 & 6.8 & 6.9 \\
\hline 1995 & 133.2 & 133.5 & 133.7 & 133.9 & 4.1 & 4.0 & 4.0 & 4.0 \\
\hline 1996 & 140.0 & 140.2 & 140.4 & 140.6 & 5.1 & 5.1 & 5.0 & 5.0 \\
\hline 1997 & 146.3 & 146.5 & 146.7 & 147.0 & 4.5 & 4.5 & 4.5 & 4.5 \\
\hline 1998 & 158.1 & 158.5 & 159.0 & 159.6 & 8.1 & 8.2 & 8.3 & 8.5 \\
\hline 1999 & 159.8 & 160.3 & 160.9 & 161.6 & 1.1 & 1.2 & 1.2 & 1.3 \\
\hline
\end{tabular}

Source: Authors' calculations.

TABLE 6

Social cost of living indices and inflation rates in Korea

\begin{tabular}{|c|c|c|c|c|c|c|c|c|}
\hline \multirow{3}{*}{ Years } & \multicolumn{8}{|c|}{ Based on interdependent social welfare function } \\
\hline & \multicolumn{4}{|c|}{$\begin{array}{l}\text { Social Cost Living Index }(1990=100) \\
\text { when inequality aversion parameter }(k) \\
\text { is equal to }\end{array}$} & \multicolumn{4}{|c|}{$\begin{array}{c}\text { Annual Inflation rate } \\
\text { when inequality aversion parameter }(k) \\
\text { is equal to }\end{array}$} \\
\hline & 0 & 1 & 2 & 3 & 0 & 1 & 2 & 3 \\
\hline 1990 & 100.0 & 100.0 & 100.0 & 100.0 & - & - & - & - \\
\hline 1991 & 108.7 & 109.0 & 109.1 & 109.2 & 8.7 & 9.0 & 9.1 & 9.2 \\
\hline 1992 & 114.9 & 115.2 & 115.3 & 115.4 & 5.7 & 5.7 & 5.7 & 5.7 \\
\hline 1993 & 120.1 & 120.3 & 120.4 & 120.5 & 4.5 & 4.4 & 4.4 & 4.4 \\
\hline 1994 & 128.0 & 128.4 & 128.6 & 128.8 & 6.6 & 6.8 & 6.8 & 6.9 \\
\hline 1995 & 133.2 & 133.6 & 133.8 & 133.9 & 4.1 & 4.0 & 4.0 & 4.0 \\
\hline 1996 & 140.0 & 140.3 & 140.5 & 140.6 & 5.1 & 5.0 & 5.0 & 5.0 \\
\hline 1997 & 146.3 & 146.6 & 146.8 & 146.9 & 4.5 & 4.5 & 4.5 & 4.5 \\
\hline 1998 & 158.1 & 158.7 & 159.1 & 159.4 & 8.1 & 8.3 & 8.4 & 8.5 \\
\hline 1999 & 159.8 & 160.6 & 161.1 & 161.4 & 1.1 & 1.2 & 1.2 & 1.3 \\
\hline
\end{tabular}

Source: Authors' calculations.

The results show that the inflation rate in Korea has generally been very high. The inflation rate rose to more than 8 percent in the 1997-98 period, when Korea was struck by a very severe economic crisis. The Korean won depreciated substantially, which fuelled inflation. However, in the subsequent period, the inflation rate dropped to just over 1 percent, which was mainly due to a drastic contraction of the aggregate GDP. It is interesting to note that increasing the value of the inequality aversion parameter does not change much the annual inflation rates, as is indicated by Figure 3. It means that the impact of relative price changes on inequality is very small in Korea. This is also indicated by the changes in inequality due to price changes, as presented in Table 7. It is also interesting to note that since the economic crisis hit Korea in 1997, price changes have increased inequality, which implies that the price changes during the crisis period hurt the poor proportionally more than the rich. 
FIGURE 3

\section{Inflation rates in Korea}

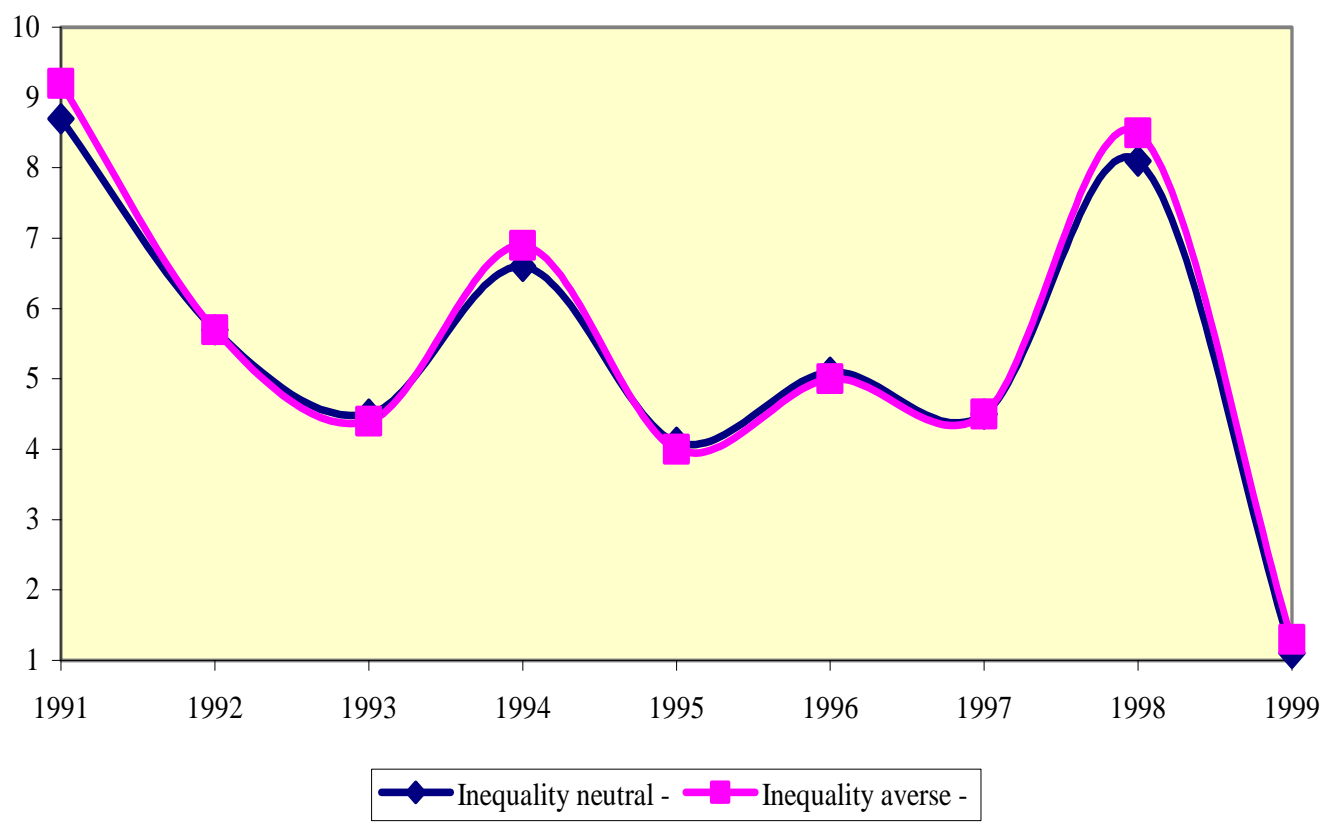

TABLE 7

Measuring the impact of price changes on inequality in Korea

\begin{tabular}{|c|c|c|c|c|c|c|}
\hline \multirow[t]{2}{*}{ Years } & \multicolumn{3}{|c|}{$\begin{array}{c}\text { Inequality measures } \\
\text { when inequality aversion parameter }(k) \\
\text { is equal to }\end{array}$} & \multicolumn{3}{|c|}{$\begin{array}{l}\text { Annual percentage change in inequality } \\
\text { when inequality aversion parameter }(k) \\
\text { is equal to }\end{array}$} \\
\hline & $1^{*}$ & 2 & 3 & 1 & 2 & 3 \\
\hline 1990 & 29.9 & 39.4 & 44.7 & - & - & - \\
\hline 1991 & 30.1 & 39.7 & 44.9 & 0.7 & 0.6 & 0.6 \\
\hline 1992 & 30.1 & 39.7 & 45.0 & 0.2 & 0.2 & 0.2 \\
\hline 1993 & 30.0 & 39.7 & 44.9 & -0.3 & -0.2 & -0.2 \\
\hline 1994 & 30.3 & 39.9 & 45.2 & 0.8 & 0.7 & 0.7 \\
\hline 1995 & 30.2 & 39.9 & 45.2 & -0.2 & -0.1 & -0.1 \\
\hline 1996 & 30.2 & 39.9 & 45.2 & -0.1 & -0.0 & -0.0 \\
\hline 1997 & 30.3 & 40.0 & 45.3 & 0.3 & 0.4 & 0.4 \\
\hline 1998 & 30.9 & 40.9 & 46.4 & 2.0 & 2.2 & 2.2 \\
\hline 1999 & 31.2 & 41.3 & 46.8 & 1.1 & 1.1 & 1.0 \\
\hline $90-99$ & - & - & - & 4.6 & 4.8 & 4.8 \\
\hline
\end{tabular}

* is the Gini index.

Source: Authors' calculations.

The impact on inequality of changes in relative prices depends on how great is the variation in consumption patterns of the population across income groups. Since Korea is a very homogeneous country with relatively low inequality, we would expect that the impact of changes in relative prices on inequality will be small. This is perhaps the reason why the impact of prices on inequality in Korea is lower than that in Thailand, where inequality is very high. This suggests that social costs of living indices are more important in high inequality countries than in low inequality countries with homogeneous population. 
Next, we compute the superlative social cost of living indices for Korea. In computing these indices, we had to compute the social elasticities for every year from 1990 to 1999. The results are presented in Tables 8 and 9 . It can be seen that the inflation rates computed from superlative social cost of living indices are not very different from the social cost of living indices based on fixed social weights. This implies that the substitution bias captured by the superlative indices is very small, being almost negligible. These results may suggest that fixed social weights provide reasonably accurate estimates of inflation rates in Korea. ${ }^{15}$

TABLE 8

Superlative social cost of living indices and inflation rates in Korea

\begin{tabular}{|c|c|c|c|c|c|c|c|c|}
\hline \multirow{3}{*}{ Years } & \multicolumn{8}{|c|}{ Based on Atkinson's social welfare function } \\
\hline & \multicolumn{4}{|c|}{$\begin{array}{c}\text { Social Cost Living Index }(1990=100) \\
\text { when inequality aversion parameter }(k) \\
\text { is equal to }\end{array}$} & \multicolumn{4}{|c|}{$\begin{array}{c}\text { Annual Inflation rate } \\
\text { when inequality aversion parameter }(k) \\
\text { is equal to }\end{array}$} \\
\hline & 0 & 1 & 2 & 3 & 0 & 1 & 2 & 3 \\
\hline 1990 & 100.0 & 100.0 & 100.0 & 100.0 & - & - & - & - \\
\hline 1991 & 108.7 & 108.9 & 109.0 & 109.2 & 8.7 & 8.9 & 9.0 & 9.2 \\
\hline 1992 & 114.9 & 115.1 & 115.2 & 115.4 & 5.7 & 5.7 & 5.7 & 5.7 \\
\hline 1993 & 120.2 & 120.3 & 120.4 & 120.6 & 4.6 & 4.5 & 4.5 & 4.5 \\
\hline 1994 & 128.1 & 128.3 & 128.6 & 128.8 & 6.6 & 6.7 & 6.8 & 6.8 \\
\hline 1995 & 133.5 & 133.7 & 133.9 & 134.1 & 4.2 & 4.2 & 4.2 & 4.1 \\
\hline 1996 & 140.6 & 140.8 & 140.9 & 141.1 & 5.3 & 5.3 & 5.3 & 5.2 \\
\hline 1997 & 147.2 & 147.4 & 147.6 & 147.8 & 4.7 & 4.7 & 4.7 & 4.8 \\
\hline 1998 & 159.5 & 160.0 & 160.6 & 161.2 & 8.4 & 8.6 & 8.8 & 9.0 \\
\hline 1999 & 161.2 & 161.8 & 162.4 & 163.0 & 1.0 & 1.1 & 1.1 & 1.1 \\
\hline
\end{tabular}

Source: Authors' calculations.

TABLE 9

Superlative social cost of living indices and inflation rates in Korea

\begin{tabular}{|c|c|c|c|c|c|c|c|c|}
\hline \multirow[t]{2}{*}{ Years } & \multicolumn{4}{|c|}{$\begin{array}{l}\text { Social Cost Living Index }(1990=100) \\
\text { when inequality aversion parameter }(k) \\
\text { is equal to }\end{array}$} & \multicolumn{4}{|c|}{$\begin{array}{c}\text { Annual Inflation rate } \\
\text { when inequality aversion parameter }(k) \\
\text { is equal to }\end{array}$} \\
\hline & 0 & 1 & 2 & 3 & 0 & 1 & 2 & 3 \\
\hline 1990 & 100.0 & 100.0 & 100.0 & 100.0 & - & - & - & - \\
\hline 1991 & 108.7 & 109.0 & 109.1 & 109.1 & 8.7 & 9.0 & 9.1 & 9.1 \\
\hline 1992 & 114.9 & 115.1 & 115.3 & 115.4 & 5.7 & 5.7 & 5.7 & 5.7 \\
\hline 1993 & 120.2 & 120.3 & 120.4 & 120.5 & 4.6 & 4.5 & 4.5 & 4.5 \\
\hline 1994 & 128.1 & 128.4 & 128.6 & 128.7 & 6.6 & 6.7 & 6.8 & 6.8 \\
\hline 1995 & 133.5 & 133.8 & 133.9 & 134.0 & 4.2 & 4.2 & 4.1 & 4.1 \\
\hline 1996 & 140.6 & 140.8 & 141.0 & 141.1 & 5.3 & 5.3 & 5.2 & 5.2 \\
\hline 1997 & 147.2 & 147.5 & 147.6 & 147.7 & 4.7 & 4.7 & 4.7 & 4.7 \\
\hline 1998 & 159.5 & 160.3 & 160.7 & 160.9 & 8.4 & 8.7 & 8.8 & 8.9 \\
\hline 1999 & 161.2 & 162.0 & 162.5 & 162.8 & 1.0 & 1.1 & 1.1 & 1.1 \\
\hline
\end{tabular}

Source: Authors' calculations.

There can be many reasons for substitution bias being so small in Korea. One possible reason may be that the superlative index is underestimating the true cost of living index. This is because superlative index is a close approximation if preferences are homothetic (income elasticities are unitary). This may be a strong requirement. Another reason may be that we have not used sufficiently disaggregated commodity groups. Finally, in countries such as the United States, people have a much greater choice of commodities and therefore greater possibilities for substitution. 


\section{CONCLUDING REMARKS}

In this paper we have developed a new methodology to compute social cost of living indices. These indices indicate whether or not price changes have a favourable or unfavourable impact on the welfare of the poor. The application of this methodology to the Thai and Korean data shows that the price changes have adversely affected the poor more than the non-poor.

Thailand has very high income inequality which has been increasing more or less monotonically (Kakwani, 1997). The government of Thailand has been deeply concerned by the increasing trend in inequality. To formulate policies to reduce inequality, it is important to know the causes of the increase in inequality. This paper has provided a useful link between price changes and income inequality.

The impact of changes in relative prices on inequality depends on how great is the variation in consumption patterns of the population across income groups. Since Korea is a very homogeneous country with relatively low inequality, we would expect that the impact of changes in relative prices on inequality will be small. This is probably the reason why the impact of prices on inequality in Korea is lower than that in Thailand, where inequality is very high. This suggests that social costs of living indices are more important in high inequality countries than in low inequality countries with homogeneous population.

In this paper we have attempted to correct for the substitution bias by calculating the superlative social cost of living indices. These indices can be computed using the usual household surveys without requiring panel data.

Our empirical results assume that all households face the same prices for various commodities. This is an unrealistic assumption because regional price differences exist in both Thailand and Korea. Fortunately, the information on regional prices is generally available in many countries. It would therefore be a basis for worthwhile research in future to extend the methodologies presented in this paper to take account of regional price differences. 


\section{REFERENCES}

Amble, N. and Stewart, K, (1994), "Experimental Price Index for Elderly Consumers," Monthly Labour Review, May 1994, 117:5, 11-16

Atkinson, A.B. (1970), "On the Measurement of Inequality", Journal of Economic Theory 2, 244-63.

Boskin, M.J., Dulberger, E.R., Gordon, R.J., Griliches, Z., and Jorgenson, W., (1998), “Consumer Prices, the Consumer Price Index, and the Cost of Living", Journal of Economic Perspectives, Vol. 12, 3-26.

Boskin, M.J., Hurd, M. (1985), "Indexing Social Security Benefits: A Separate Price Index for the Elderly," Public Finance Quarterly, October, 13:4, 436-449.

Braithwait, S.D. (1975), "Consumer Demand and Cost of Living Indexes for the U.S.:

An Empirical Comparison of Alternative Multi-Level Demand Systems", BLS Working Paper 45, June.

Braithwait, S.D. (1980), "Substitution Bias of the Laspeyres Price Index: An Analysis Using Estimated Cost of living Indexes", American Economic Review, March 1980, 64-77.

Christensen, Laurits R. and M. E. Manser (1974), "Cost of Living Indexes and Price Indexes for U.S. Meat and Produce: 1947-1971", National Bureau of Economic Research, Conference in Research in Income and Wealth, 40, Household Behaviour and Consumption.

Deaton, A. (1998), The Analysis of Household Surveys, World Bank: Washington DC.

Diewert, W.E. (1983), "The Theory of the Cost of living Index and the Measurement of Welfare Change", in W.E. Diewert and C. Montmarquette (eds), Price Level Measurement, Ministry of Supply and Services Canada, 163-225.

Diewert, W.E. (1990), The Economic Theory of Index Numbers, Amsterdam: North-Holland

Diewert, W.E. (1993), "Group Cost of Living Indexes: Approximations and Axiomatics", Chapter 11 in W.E. Diewert and A.O. Nakamura (eds), Essays in Index Number Theory, 1, Elsevier Science Publishers, B.V., 287-316.

Diewert, W.E. (1976), "Exact and Superlative Index Numbers", Journal of Econometrics 4, 115-145.

Diewert, W.E. (1990), Price Level Measurement, Amsterdam: North-Holland.

Diewert, W.E. (1998), "Index Number Issues in the CPI", Journal of Economic Perspectives, Vol. 12, 47-58.

Hicks, J.R. (1946), Value and Capital, Oxford: Clarendon Press.

Jorgenson, D.W. and D.T. Slesnick (1983), "Individual and Social Cost of living Indexes", In W.E. Diewert and C. Montmarquette, eds. Price Level Measurement, Ottawa: Statistics Canada, 241-336.

Kakwani, N. (1997), "Economic Growth and Income Inequality in Thailand", presented at the Final Workshop on Establishment of Key Indicators System for the 8th Plan and Monitoring and Evaluation, National Economic and Social Development Board Bangkok.

Kakwani, N. (1980), “On a Class of Poverty Measures”, Econometrica 48, 437-46.

Kakwani, N. (1977), "Applications of Lorenz Curves in Economic Analysis", Econometrica 45, 719-27. 
Kakwani, N. (1980a), Income Inequality and Poverty: Methods of Estimation and Policy Applications, Oxford University Press, New York.

Konüs, A.A. (1924), "The Problem of True Cost of Living", translated in Econometrica 7, 1939, 10-29.

Manser, M.E. (1975), "The Translog Utility Function with Changing Tastes", BLS Working Paper 33, January.

Minzly, Y. (1980) Inflation across households and the variability of inflation experienced by different groups of population, Mimeo. Bank of Israel Research Department, April 1980.

Michael, R. T. (1979) Variation across households in the rate of inflation. Journal of Money, Credit and Banking, XI. 32-46

Muellbauer, J. (1974), "Recent U.K. Experience of Price and Inequality: An Application of Cost of Living and Real Income Indices", Economic Journal, 84, 32-55.

Pollak, R.A. (1983), "The Theory of the Cost of living Index", in W.E. Diewert and C. Montmarquette (eds), Price Level Measurement, Ministry of Supply and Services Canada, 5-78.

Pollak, R.A. (1981), "The Social Cost of Living Index", Journal of Public Economics 15, 311-336.

Pollak, R.A. (1980), "Group Cost of living Indexes", American Economic Review 70, 273-278.

Pollak, R.A. (1998), "The Consumer Price Index: A Research Agenda and Three Proposals", Journal of Economic Perspectives, Vol. 12, 69-78.

Prais, S.J. (1959), “Whose Cost of living”, Review of Economic Studies, 26, 126-134.

Samuelson, P.A. and S. Swamy (1979), "Invariant Economic Index Numbers and Canonical Duality: Survey and Synthesis", American Economic Review 64, 566-93.

Sen, A.K. (1974), "International Bases of Alternative Welfare Approaches: Aggregation and Income Distribution", Journal of Public Economics 4, 387-403.

Silber, J. (1986), "Variability in the experienced rates of inflation and price index linkage to social welfare," Applied Economics, 18(1): 49-58.

Tornqvist, L. (1936), "The Bank of Finland's Consumption Price Index", Bank of Finland Monthly Bulletin 10, 1-8. 


\section{NOTES}

1. We would like to acknowledge an important contribution of Silber (1986), who proposed a class of group cost of living indices based on Atkinson's social welfare function. Our approach is based on the economic theory of index numbers whereas his approach is based on fixed basket.

2. Sen's (1974) social welfare function is a particular member of this class.

3. This function is also known as 'cost function' in the literature but we will refer to it as 'expenditure'.

4. The expenditure function has three properties:

(i). $e(u, p)$ is increasing in $u$ for every $p$.

(ii). $\mathrm{e}(\mathrm{u}, \mathrm{p})$ is (positively) linearly homogeneous in $\mathrm{p}$ for every $\mathrm{u}$, ie. $e(u, \lambda p)=\lambda e(u, p)$

(iii). $e(u, p)$ is concave in $p$ for every $u$.

5. It is essential to assume a homothetic function otherwise we will not be able to satisfy a basic requirement that if all prices increase in the same proportion, the true cost of living index should also increase by the same proportion.

6. From the property of expenditure function, we know that $e(u, \lambda p)=\lambda e(u, p)$ is always satisfied, so substituting this in (10), it is easy to see that $e(\tilde{u}, \lambda p)=\lambda e(\tilde{u}, p)$ will always be satisfied or in other words, the social expenditure function $e(\tilde{u}, p)$ is homogeneous in p. Thus, the entire class of homothetic functions in (9) will always satisfy the basic property that if all prices increase in the same proportion, the true cost of living index in (5) will also increase by the same proportion.

7. Silber's (1986) social cost of living index in our notation is given by

$$
\begin{aligned}
& S=\frac{\left[\int_{0}^{\infty}\{x L(x)\}^{(1-\varepsilon)} f(x) d x\right]^{\frac{1}{1-\varepsilon}}}{\left[\int_{0}^{\infty} x^{(1-\varepsilon)} f(x) d x\right]^{\frac{1}{(1-\varepsilon)}}} \quad \text { if } \mathcal{E} \neq 1 \\
& =\int_{0}^{\infty} \log [L(x)] f(x) d x \quad \text { if } \varepsilon=1
\end{aligned}
$$

8. See Section 10 for further discussion on this point.

9. For a detailed discussion of concentration indices, see Kakwani (1977, 1980a).

10. The discussions given in this section are motivated by the comments made by one of the referees.

11. It is not necessary that societies with higher inequality will have higher aversion to inequality. We do propose a higher inequality aversion parameter for societies with higher inequality.

12. The STATA-do file for calculating all the social cost of living indices described in this paper is available from the authors upon request.

13. Some attempts have been made to compute Laspeyres-type price indices for elderly in the Unite States (see Boskin and Hurd (1985) and Amble and Stewart (1994)). Jorgenson and Slesnick (1983) have estimated system of demand equations for different demographic groups to calculate their cost-of-living indices. For a useful discussion of this issue see Silber(1986), Michael (1979) and Minzly(1980).

14. As $k$ increases, greater weight is given to the persons at the bottom of the expenditure distribution, which means that if inflation rate increases with $k$, the ultra poor are more adversely affected than just poor.

15. Many empirical studies have indicated that the substitution bias is small enough that it can probably be neglected. (Braithwait (1975), Christensen and Manser (1974) and Manser (1975). Boskin, Dulberger, Gordon, Griliches and Jorgenson (1998) report a substitution bias of .4 percentage points per year, which is much larger than our estimates for Korea. 
International Poverty Centre SBS - Ed. BNDES, $10^{\circ}$ andar 70076900 Brasilia DF Brazil

povertycentre@undp-povertycentre.org www.undp.org/povertycentre

Telephone +55 6121055000

Fax +55 6121055001 